\title{
The hematopoietic stem cell and its niche: a comparative view
}

\author{
Julian A. Martinez-Agosto, ${ }^{1,2}$ Hanna K.A. Mikkola, ${ }^{3,4,5}$ Volker Hartenstein, ${ }^{3}$ \\ and Utpal Banerjee $e^{3,4,5,6,7}$

\begin{abstract}
${ }^{1}$ Department of Human Genetics and Department of Pediatrics, David Geffen School of Medicine, University of California at Los Angeles, Los Angeles, California 90095, USA; ${ }^{2}$ Mattel Children's Hospital, University of California at Los Angeles, Los Angeles, California 90095, USA; ${ }^{3}$ Department of Molecular, Cellular and Developmental Biology, University of California at Los Angeles, Los Angeles, California 90095, USA; ${ }^{4}$ Institute for Stem Cell Biology and Medicine, University of California at Los Angeles, Los Angeles, California 90095, USA; ${ }^{5}$ Molecular Biology Institute, University of California at Los Angeles, Los Angeles, California 90095, USA; ${ }^{6}$ Department of Biological Chemistry, University of California at Los Angeles, Los Angeles, California 90095, USA
\end{abstract}

Stem cells have been identified as a source of virtually all highly differentiated cells that are replenished during the lifetime of an animal. The critical balance between stem and differentiated cell populations is crucial for the longterm maintenance of functional tissue types. Stem cells maintain this balance by choosing one of several alternate fates: self-renewal, commitment to differentiate, and senescence or cell death. These characteristics comprise the core criteria by which these cells are usually defined. The self-renewal property is important, as it allows for extended production of the corresponding differentiated cells throughout the life span of the animal. A microenvironment that is supportive of stem cells is commonly referred to as a stem cell niche. In this review, we first present some general concepts regarding stem cells and their niches, comparing stem cells of many different kinds from diverse organisms, and in the second part, we compare specific aspects of hematopoiesis and the niches that support hematopoiesis in Drosophila, zebrafish and mouse.

The developmental characteristics of stem cells and their niche

In Planarians, pluripotent cells termed neoblasts can give rise to all cell types in response to injury, and these cells persist in the adult organism (Reddien and Alvarado 2004). As few as 10,000 cells are capable of regenerating all missing tissues from a small population of neoblasts (Montgomery and Coward 1974; Saló 2006). Similarly, plants possess meristem-derived cells that can be reprogrammed to all cell types (Verdeil et al. 2007). These represent pluripotent stem cell populations that are

[Keywords: Stem cell; niche; hematopoiesis; zebrafish; Drosophila; blood]

${ }^{7}$ Corresponding author.

E-MAIL banerjee@mbi.ucla.edu; FAX (310) 206-9062.

Article is online at http://www.genesdev.org/cgi/doi/10.1101/gad.1602607. maintained throughout the life of the organism and contrasts with mouse and human embryonic stem (ES) cells, which are also pluripotent but are derived from cells found only transiently in the developing embryo. Definitions of stem cells are, of necessity, context and organism dependent. For example, in the short-lived fruit fly Drosophila, neuroblasts that give rise to all neural cell types in the adult brain are only transiently present during development and undergo extinction during metamorphosis (Urbach and Technau 2004). In contrast, embryonic neuroblasts in the longer-lived cricket persist in the adult and are maintained throughout the life span of the insect, akin to the neural stem cells of the adult mammalian brain (Cayre et al. 2007). Thus, persistence through life is not the single defining criterion for stemness.

Developmental biologists have long defined progenitors as cells with proliferative capacity that may or may not be committed to a lineage choice but are not terminally differentiated. A precursor cell type is usually, although not always, post-mitotic, but has the capacity to assume one of several differentiated fates. As an example, the Drosophila eye develops from a sheet of epithelium known as the eye disc that includes a group of homogeneous progenitor cells committed to the eye fate (Voas and Rebay 2004). Once such cells cross a morphogenetic front, they become post-mitotic precursors that still have the capacity to differentiate into many neuronal and nonneuronal cell types (Nagaraj and Banerjee 2003; Wernet and Desplan 2004). Neither these progenitors nor the precursors are called stem cells, as they do not follow some of the crucial behaviors reserved for such cells. Thus, possession of multipotential capacity is also not a sufficient criterion for being classified as a stem cell (Fig. 1).

In fact, only a small subset of progenitor cells are usually termed stem cells. For example, the hematopoietic stem cell (HSC) (Wu et al. 1967, 1968), perhaps the bestdescribed stem cell population in mammals, arises from 


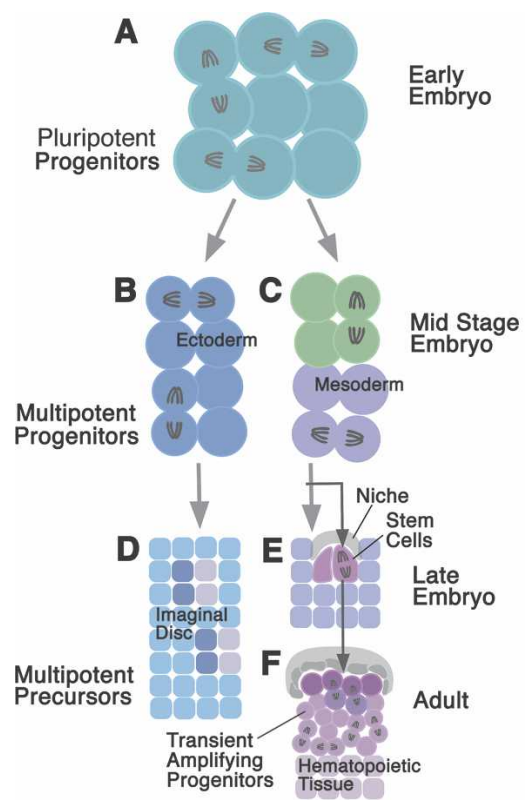

Figure 1. Stem cells in the context of development. $(A-C)$ Embryos consist of mitotically dividing cells called progenitors. Progenitors can be pluripotent (e.g., blastomeres in mammalian embryos) or multipotent (e.g., ectoderm or mesoderm). (D) At later developmental stages, cells exit the mitotic cycle. Generally called precursors, these cells can still be multipotent (e.g., cells of imaginal discs in Drosophila). At some point precursors become committed to a particular fate and differentiate. $(E)$ Stem cells (e.g., HSCs) develop from embryonic progenitors that are prevented from exiting the mitotic cycle by specific microenvironments, called niches. $(F)$ In the adult organism, stem cells undergo asymmetric cell divisions and produce mitotically active daughter cells also called progenitors ("transient amplifying cells").

a transiently occurring mesodermal progenitor that is not classified as a stem cell (Fig. 1). As not all criteria can be met for all classes of stem cells, it is important to establish a minimum set that would allow one to define a stem cell and its environmental niche. The most stringent definitions may have evolved for the mammalian hematopoietic system that we use here as a starting point to explore the variations on this theme.

The criteria assigned as requirements in defining an HSC include (1) multipotency and asymmetric cell division as means to give rise to multiple cell types; (2) quiescence and slow self-renewal allowing for long life span; (3) niche dependence and the ability to maintain an undifferentiated state in the presence of such a niche; and (4) long-term repopulation and the ability to engraft in vivo and reconstitute the tissue upon transplantation.

\section{Potency}

The definition of a stem cell inevitably requires an assessment of its potential to give rise to a number of differentiated progeny. This potential can vary among different tissue types, and by the origin and requirement of a particular type of stem cell (Fig. 2). Totipotent stem cells are defined as those that can give rise to all tissues in an organism. ES cells would largely satisfy this criterion, but are usually called pluripotent as they originate from the inner cell mass of the embryo and give rise to all tissues in vivo, except trophoblasts (Rossant 2006). In fact, ES cells can also generate trophoblasts in vitro, demonstrating the unique plasticity of these cells and the likelihood that they truly represent a bona fide stem cell population (Schenke-Layland et al. 2007). Developmentally, there is no requirement for an ES cell to be maintained throughout life, and as yet, no clear evidence exists for a niche that maintains them. In fact, it is only when ES cells are grown in the laboratory that they seem to self-renew indefinitely utilizing cellular or noncellular substrates as a niche. In contrast to ES cells, adult stem cells are more limited in their potency. HSCs constitute the classic example of a multipotent stem cell, which can give rise to a large repertoire of differentiated cell types belonging to the lymphoid and myeloid lineages. However, stem cells can also be unipotent if they are only capable of giving rise to a single cell type that is constantly produced throughout the life span of the organism. The best-described example is the germline stem cell (GSC), which can generate a single differentiated cell fate: either an egg or a sperm. While potency can be used as a criterion to define a stem cell, the functional needs of each tissue will determine the spectrum of cell types generated. It is therefore legitimate to call a cell a stem cell even if it only generates a single cell type. Recent studies suggest that potency could be reprogrammed by interfering with a cell's epigenetic state. For example, skin fibroblasts can be reprogrammed to give rise to all cell types of a mouse if proteins associated with ES stemness are expressed in these cells (Maherali et al. 2007; Okita et al. 2007; Wernig et al. 2007). This emerging concept of cellular reprogramming demonstrates the dynamic and reversible nature of potency.

\section{Asymmetric cell division}

In its canonical view, a stem cell is presented as one that divides asymmetrically to produce a copy of itself and a second cell that is on its path to differentiate (Fig. 3).
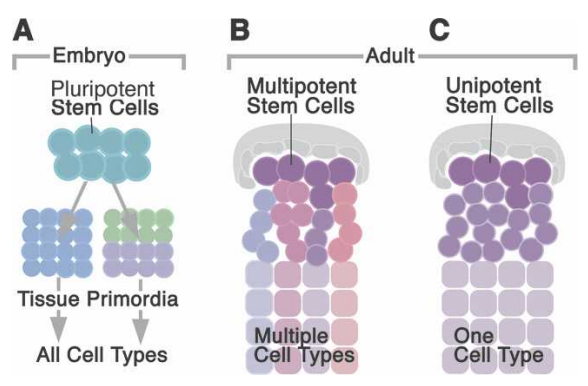

Figure 2. Stem cell potency. (A) ES cells of mammalian embryos are pluripotent. $(B)$ Multipotent adult stem cells can give rise to multiple different lineages (e.g., HSCs). (C) Unipotent adult stem cells produce a single cell type (e.g., GSCs). 


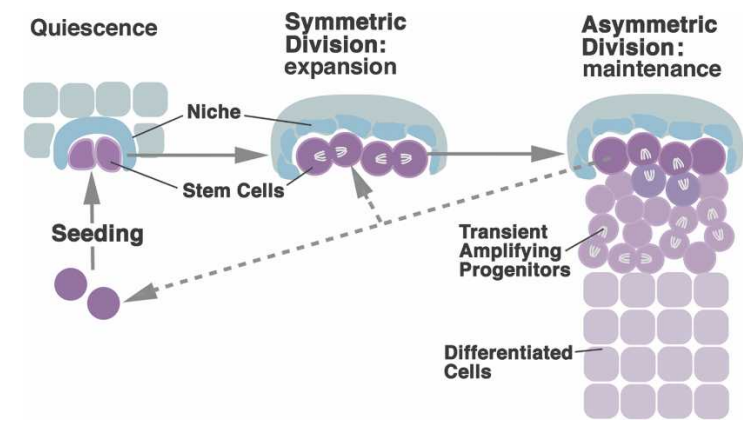

Figure 3. Stem cell dynamics. Stem cells are generated in the embryo. They persist in specific niches where they can remain mitotically quiescent for long periods of time. Stem cells expand their numbers as they self-renew by symmetric division. They can also maintain their numbers and produce rapidly dividing progenitors by asymmetric division.

That second cell may have one of many characteristics depending on the context of its development. In certain instances, that cell would be a precursor type that undergoes terminal differentiation. For example, in the ventricular zone of the developing vertebrate cerebral cortex, neural stem cells divide asymmetrically to give rise to progeny that will differentiate upon migration to the appropriate cortical layer (Rakic 2006). Alternatively, a cell generated from asymmetric division could itself be a progenitor that amplifies itself and then differentiates into one of many cell types. Such progenitors are often referred to as transient amplifying (TA) cells. These cells have a finite proliferative potential, and eventually exhaust themselves once they give rise to differentiated progeny. For example, in the mouse small intestine epithelium, stem cells give rise to TA cells that go on to differentiate into various cell types of the villi crypts (Leedham et al. 2005). TA progenitor cells in the skin can be distinguished by their expression of Keratin-15 from the p63-expressing stem cells from which they originate (Tiede et al. 2007). Similarly the murine corneal epithelium contains a population of stem cells in the limbus that express molecular markers absent from the TA cells of the central corneal epithelium (Zhou et al. 2006). Finally, an asymmetric cell division from a stem cell could generate a copy of itself and a second stem cell with a more limited potential for self-renewal. This is exemplified by the short-term repopulating progenitors of the vertebrate bone marrow (Morrison et al. 1995). The true $\mathrm{HSC}$, as well as the one that is generated, share the same potential; however, only one is capable of long-term reconstitution of the adult bone marrow.

In reality, asymmetric cell division has more often been proposed as a concept than has been demonstrated through direct observation. Asymmetric cell division has been most convincingly evidenced in the generation of the Drosophila germline. While there are many similarities between male and female germlines, there are differences in the mechanisms that regulate asymmetric cell division of each stem cell (Fuller and Spradling 2007). In both germlines, as the stem cell undergoes cell division, the mitotic spindle is oriented at a right angle to the cells of the niche, allowing one cell to remain in contact with the niche while the other moves away and differentiates. In the Drosophila testis, as the stem cell divides, the centrosome migrates to the cortex where the cell attaches to the so-called hub cells. As cell division continues, the duplicated centrosome migrates to the opposite side of the cell while the centrosome that was originally present in the stem cell is asymmetrically inherited and remains within the daughter cell closest to the niche. The daughter centrosome is retained by the cell that differentiates into a sperm (Yamashita et al. 2007). This asymmetric localization of centrosomes establishes the orientation of the mitotic spindle perpendicular to the hub and thus determines the asymmetric behavior in the stem cell niche and ensures that the renewed stem cell remains in close contact to the niche. In the Drosophila ovary (Fig. 4), orientation of the mitotic spindle is mediated by the spectrosome, a structure composed of cytoskeletal proteins located at the apical side of the stem cell, where it interacts with the niche cells (cap cells) through extracellular matrix components (Lin and Spradling 1995; Deng and Lin 1997). As the spectrosome is always retained in the stem cell, it determines the axis of asymmetry and allows for maintenance of the stem cell population.

Other forms of direct evidence for asymmetric cell division come from the immunolocalization of products that may be differentially distributed between two daughter cells. In well-studied examples in both vertebrate and invertebrate species, apical-basal polarity complexes can be found asymmetrically positioned in a neuroblast and upon cell division, such complexes can cause asymmetric distribution of cell fate determinants, such

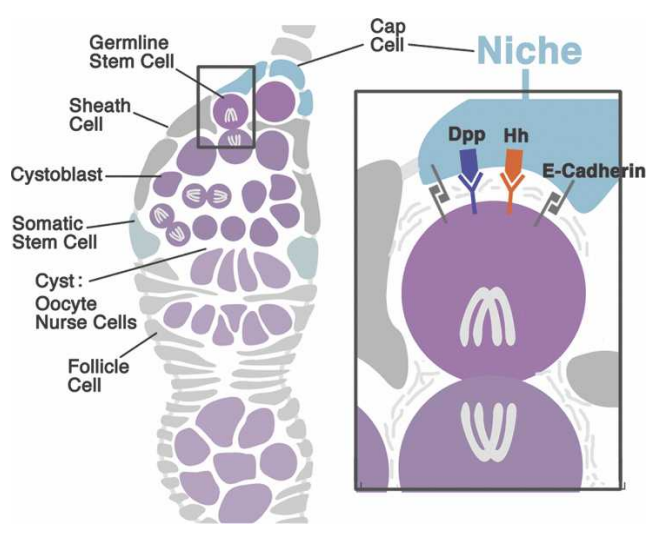

Figure 4. Structure and function of the niche in the Drosophila ovary. GSCs are in close contact with a group of somatic cells, called cap cells, that constitute the niche. Niche-derived signals-among them the BMP2/4 homolog Dpp and Hh-maintain self-renewal and inhibit differentiation of the GSCs. Along with structural proteins, such as E-Cadherin, and cytoskeletal complexes, these signals also control the vertical orientation of the mitotic spindle. As a result of this spindle orientation, one of the two daughter cells of a GSC will be pushed out of the niche and enter a pathway that leads to the differentiation of haploid oocytes and nurse cells. 
as Numb, a component of the Notch pathway (Yu et al. 2006). Additional levels of regulation can be provided by asymmetric distribution of several identified proteins during progenitor cell division (Knoblich 2001; Betschinger and Knoblich 2004). Asymmetric cell division during human hematopoiesis has only been observed in vitro by identifying differentially distributed markers in the daughter cell of an HSC (Beckmann et al. 2007) and by assaying the developmental potential of this daughter cell (Ema et al. 2000; Giebel et al. 2006). Asymmetric cell division has not yet been seen or established in many developmental niches, such as in the Caenorhabditis elegans germline, Drosophila hematopoietic organ, and mouse intestinal crypts.

\section{Self-renewal and quiescence}

A hallmark of a stem cell is its ability to give rise to large numbers of differentiated cells over extended periods of time. To achieve this, not only do such cells self-renew through asymmetric divisions as described above, they may also expand their population through symmetric cell division (Fig. 3). Most stem cells appear to cycle infrequently, and their relative quiescence is considered an important aspect of their identity. Infrequent proliferation of a stem cell is important for maintaining tissue homeostasis and also prevents accumulation of excessive oncogenic events that may arise from mistakes that occur during life-long self-renewal. Mouse fetal HSCs cycle actively as they expand to seed additional sites of definitive engraftment. However, once their numbers are optimally reached, past 3 wk postnatally, mouse fetal HSCs become quiescent, particularly in the bone marrow. Some evidence suggests that the difference in selfrenewal capacities of the fetal and adult HSC is cell intrinsic and is related to its developmental stage (Bowie et al. 2007). Molecular pathways required for regulating this self-renewal may also involve reciprocal interactions between the HSC and its niche. For example, dysregulation of self-renewal and eventual myeloproliferative disorder are caused when the retinoblastoma gene is eliminated in both myeloid-derived cells and their niche but not when it is removed in one or the other individually (Walkley et al. 2007b). Similarly, the Argonaute-like protein Piwi is required in both the niche cap cells and the stem cells for the maintenance of the proper stem cell environment of the Drosophila ovary (Szakmary et al. 2005). This family of Piwi factors has emerged as a key regulator of stem cell self-renewal across species (Seto et al. 2007), from the neoblasts in planarians (Reddien et al. 2005) to the Drosophila (Cox et al. 2000) and human (Qiao et al. 2002) germlines.

Several pulse-chase technologies have been used to gauge the extent of stem cell quiescence. Cells undergoing mitotic division can be studied directly through the analysis of markers of the cell cycle, such as bromodeoxyuridine (BrdU) and phospho-Histone H3. One elegant method utilizes somatic recombination of inactive alleles in cells undergoing mitosis to produce a lacZ marker exclusively in a mitotic cell, which is then maintained in all its progeny (Harrison and Perrimon 1993). This technique identified a stem cell population in tissues where the stem cell is the only cell that divides continuously but infrequently, such as in the adult Drosophila midgut (Ohlstein and Spradling 2006) and in the germline (Margolis and Spradling 1995). But in C. elegans, the stem cell is found to readily lose BrdU due to dilution, suggesting frequent cycles of self-renewal (Crittenden et al. 2006). One popular pulse-labeling method utilizes the long-lived protein fusion of Histone H2B with GFP (H2BGFP) that incorporates into the nucleosome after each cell division. Providing a pulse of H2B-GFP expression allows direct observation of a quiescent cell that retains label after a period of time, while a cell that divides frequently eventually dilutes its H2B-GFP content. In a particularly elegant use of this technique, expression of H2B-GFP in the cells of the mouse hair follicle led to the identification of a quiescent population of stem cells in the so-called bulge region. Remarkably, these stem cells can be readily identified by the persistence of H2B-GFP retention for up to 4 mo after the initial pulse of expression (Tumbar et al. 2004; Lowry et al. 2005). It is worth noting that at least one cell division is required for incorporation of the label, which may prevent the identification of the most quiescent stem cells in a population. Taken together, quiescence seems to be a general feature of stem cells, although the rate at which these cells divide may vary depending on the context.

\section{Perdurance and repopulation}

HSCs possess the unique capability to leave their tissue of origin, enter circulation, identify and eventually relocate to an available niche elsewhere during early development (Quesenberry et al. 2005). Also, in the adult, they can leave the bone marrow and return back to it through homing mechanisms (Bhattacharya et al. 2006). These properties are exclusively the characteristic of circulating stem cells, and therefore cannot be considered among the general criteria. Nevertheless, being able to destroy existing stem cells and having the repertoire reconstructed through transplantation into sublethally irradiated mice allowed for the development of the most valuable in vivo assay for establishing the functional capabilities of human SCID repopulating cells (Lapidot et al. 1992). In the mouse, transplantation of a small number, or even a single cell, is capable of repopulating the whole bone marrow compartment (Spangrude et al. 1988; Osawa et al. 1996; Krause et al. 2001). These assays are not possible for all stem cell types and are thus limited by their technological capabilities. However, reconstitution of stem cells has been achieved in the mouse skin (Terunuma et al. 2004), HSCs in zebrafish (Traver et al. 2003, 2004), and in the reconstitution of spermatogenesis after spermatogonial stem cell transplantation (Brinster 2002). Although stem cell transplantation is not yet feasible in all systems, technological advances might eventually allow for transfer of stem cells to all tissues from which they originate, and in conjunction with their appropriate niche, be able to establish their 
reconstitution potential as a powerful criterion for their stemness.

\section{Niche dependence}

Key properties of stem cells such as their self-renewal and developmental capacity can be controlled in a nonautonomous manner by their cellular microenvironment. Such a microenvironment is usually referred to as a stem cell niche (Fig. 3). As is the case for the stem cells themselves, the criteria that define niches are not invariant. From the standpoint of developmental biology, virtually all differentiated cells acquire their fate through some signaling interactions with neighboring cells. Even in C. elegans, where the lineage is invariant under normal circumstances, cell fate is not devoid of plasticity, and pluripotent precursors will often give rise to a different fate when found in a new microenvironment (Albertson et al. 1978). It will therefore not be useful to automatically call the microenvironment from which each stem cell initially emerges from a progenitor group as a niche, even if such a developmental microenvironment engages in extensive cell-cell interaction. A niche is a group of cells that allows a stem cell to maintain its identity (Scadden 2006). The cells of a niche will prevent a previously specified cell from losing its stemness through loss of quiescence and potency or precocious differentiation. In the best demonstrations of a niche, a specific signaling pathway or a cell adhesion molecule is identified that allows the niche cells to maintain contact with stem cells and typically in the absence of such a mechanism, the stem cells leave their niche and either divide, differentiate, or apoptose (Scadden 2006).

There can be several different developmental strategies by which niche cells distinguish themselves from the stem cell population they maintain (Fig. 5). To begin with, stem cells could simply survive autonomously, maintaining each others' stemness. For example, it is unclear if the cells of the embryonic inner cell mass require a niche for their maintenance or if interaction between stem cells is sufficient for maintenance of this population in vivo (Biswas and Hutchins 2007). Normally, ES cells derived from the inner cell mass require a layer of fibroblast cells (feeder layer) to maintain their self-renewal in culture. However, under in vitro culture conditions in which this feeder layer is removed but the conditioning medium is supplemented with FGF, ES cells have been reported to give rise to fibroblast-like cells that secrete IGF-1 and TGF- $\beta$, which then allow other ES cells to self-renew and be maintained (Bendall et al. 2007). These in vitro results could be interpreted to suggest that a single population of cells gives rise to both the niche and the stem cells they support. This work suggests that at least in vitro, ES cells could generate a population of fibroblast-like cells, which produce signals that maintain the extended self-renewal and pluripotency of the ES cell.

The niche and the stem cells may arise from the same progenitor population, as is the case of the origin of HSC and endothelial cells of the dorsal aorta, which share a common progenitor in their ancestry (Jaffredo et al. 1998), and the placenta in mice (Gekas et al. 2005). The vascular endothelium then serves as a niche for maintaining this population of cells on their way to other sites of definitive hematopoiesis (Nikolova et al. 2007). The cells of the Drosophila hematopoietic niche develop from a pool of progenitors shared in common with the eventual blood cell precursors, but the cells of the niche and the hemocytes they support are specified independently of each other during embryogenesis (Mandal et al. 2007). Finally, a niche could be derived completely separately from the stem cell, as is the case for the bone marrow hematopoietic niche, which utilizes signals derived from osteoblasts and mesencymal stromal cells, both of which, although mesodermal, have different developmental origins from the HSC (Wilson and Trumpp 2006).

While the concept of a niche was initially proposed by Schofield (1978) in mouse hematopoiesis, it is probably fair to say that the in vivo signaling properties of niche cells were first discovered in the invertebrate germline. The Drosophila male GSCs divide asymmetrically, giving rise to one stem cell and one goniablast that initiates differentiation (Yamashita et al. 2005). In adult male testes, eight to 10 GSCs surround the somatic apical hub. The hub functions as a stem cell niche by secreting a signaling ligand, Unpaired (Upd) (Tulina and Matunis 2001). Upd binds the transmembrane receptor Domeless, activating the Janus kinase Hopscotch and the transcription factor STAT92E (Arbouzova and Zeidler 2006). Interestingly, the JAK-STAT pathway also regulates hematopoiesis in Drosophila (Krzemien et al. 2007), suggesting that this pathway is a common mechanism for niche signaling in somatic tissues as well. In the Drosophila ovary (Fig. 4), two to three GSCs are located adjacent to cap cells at the distal tip of a germarium (Fuller and Spradling 2007). The cap cells provide signaling molecules, such as Decapentaplegic (Dpp; the Drosophila ortholog of BMP-2), that regulate the self-renewal and undifferentiated properties of the GSCs (Xie and Spradling 1998). Each stem cell divides asymmetrically to give rise to a differentiated cystoblast, which eventually forms part of the egg after several rounds of cell division. If one GSC is removed through inactivation of the Dpp pathway, the remaining GSC divides symmetrically to produce an additional GSC to replace it, rather than dividing asymmetrically, as it normally does to produce a cystoblast (Xie and Spradling 2000). This demonstrated that the GSCs of the ovary truly reside in a niche that regulates their maintenance. A similar role for the BMP signaling pathway in stem cell maintenance and selfrenewal has been shown in many other systems. For example, BMPs are required for maintenance of ES cells (Ying et al. 2003). In contrast, BMP signaling in the mouse bone marrow negatively regulates the size of the niche, which in turn, affects HSC self-renewal and number (Zhang et al. 2003). In other systems, like the dental epithelium (Wang et al. 2007), the intestinal epithelium (He et al. 2004), and the hair follicle (Kobielak et al. 2007) stem cells, BMP signaling is required to maintain their 




Figure 5. Developmental relationships of stem cells and their niches. Stem cells and niche cells and their primordia are depicted in different colors (see color key at bottom left). (A) Stem cell pool produces its own niche. For example, cells of the inner cell mass in the embryo are transient in vivo, but can generate ES cells when cultured in vitro with feeder layers that maintain their self-renewal. Under appropriate culture conditions, ES cells can give rise to fibroblast-like cells that can act as niche to maintain self-renewal. $(B)$ Stem cells and niche derive from the same embryonic primordium. Example shown: Drosophila hematopoietic organ (lymph gland). Stem cell pool and niche (PSC) originate in the cardiogenic mesoderm of the embryo. The expression of specific transcription factors (Antp) determines the fate of a subset of cardiogenic mesodermal cells as the prospective PSC, while the remainder of the cells generate the pool of blood stem cells. Both lineages remain separate. (Bottom panel) In larval lymph gland, cells adjacent to the PSC act as blood stem-like cells and form the tightly packed, slowly proliferating medullary zone; toward the periphery (cortical zone), cells proliferate more rapidly and differentiate into blood cells. $(C)$ Stem cells and niche derive from different, spatially separate primordia. Example: mammalian hematopoietic organ (bone marrow). Blood stem cells (HSCs) are derived from a part of the embryonic mesoderm called the AGM mesoderm. HSCs migrate through the blood vessels toward the bone. Osteoblasts, derived from the bone primordia, act as niche. $(D)$ Stem cells and niche originate from different, adjacent primordia. In the mammalian intestinal epithelium, intestinal stem cells form an integral part of the endodermally derived epithelium and are located at the boundary between villi and crypts. Evidence suggests that neighboring mesenchymal cells, derived from the splanchnic mesoderm that surrounds the endoderm, function as a niche.

quiescence. In those systems, BMP regulates the expression and function of Wnt proteins, which are required for stem cell maintenance (Reya and Clevers 2005).

In the C. elegans germline, mitotically active immature germ cells located at its distal end are displaced more proximally by newly generated cells and go on to progressively mature into gametes. The cells located at the distal end are directly juxtaposed to a so-called somatic distal tip cell (DTC), which, utilizing the Notch pathway, is required for maintenance of mitosis within this population (Austin and Kimble 1987). Notch signaling regulates pumilio- and nanos-like RNA-binding proteins that repress expression of differentiation factors and promote mitosis in stem cells (Hansen et al. 2006). Interestingly, similar proteins involved in translational control are also required for stem cell maintenance in planaria (Salvetti et al. 2005), the Drosophila ovary (Wang and Lin 2004), mammalian germline (Xu et al.
2007), and HSCs (Spassov and Jurecic 2003). In the $C$. elegans germline it has been suggested that about five cells that are in most direct contact with the DTC likely represent the stem cell population, with the DTC serving as a niche regulating their maintenance (Kimble and Crittenden 2007). From these and other studies emerged the general concept that the niche cells signal directly to the stem cell in order to maintain its potency and undifferentiated state.

Several common characteristics of a niche microenvironment have emerged from comparative studies of different tissue-specific stem cell types. These include the use of cell adhesion molecules to maintain contact or close proximity between the niche and the stem cell (Gonzalez-Reyes 2003), asymmetric distribution of signaling molecules and their receptors (Morrison and Kimble 2006), apposition of differentiating precursors between differentiated cells and the stem cell (Díaz-Flores 
et al. 2006), and contact with the outside environment (Scadden 2006). Perhaps most striking is the heterogeneity of the physical relationship between the stem cell and its niche across different organisms. In the C. elegans germline, the DTC extends long thin processes the length of several cell diameters that wrap around the potential stem cells and the transiently amplifying cells that they generate (Crittenden et al. 2006). This is similar to the Drosophila hematopoietic organ, the lymph gland, where cells from its niche extend long thin processes that interdigitate with the undifferentiated stemlike cells of the quiescent medullary zone (Mandal et al. 2007). In the Drosophila germline, cell adhesion molecules rather than cellular processes are essential for niche-dependent regulation of stem cell function. Removal of these cell adhesion molecules causes stem cells to drift away and differentiate prematurely (Song et al. 2002). Best described and most evolutionarily conserved are the cadherin class of membrane cell adhesion molecules, central in regulating the physical interaction between stem cell and niche across many species (Halbleib and Nelson 2006). In the Drosophila ovary, removal of DE-cadherin from the niche cap cells causes premature differentiation and loss of GSCs (Godt and Tepass 1998; Song et al. 2002). In the mouse adult bone marrow, Ncadherin is expressed in the HSC and the spindle-shaped osteoblastic cells of the niche (Zhang et al. 2003). In Drosophila, DE-cadherin is expressed by the stem-like hematopoietic cells of the lymph gland (Jung et al. 2005) and the neuroblasts of the developing brain, where it is required for their self-renewal (Dumstrei et al. 2003). While the function of DE-cadherin in the Drosophila hematopoietic organ remains to be determined, it is clear that this class of cell adhesion molecules represents an essential component of the stem cell niche.

\section{A comparative view of Drosophila, zebrafish, and mouse hematopoietic niches}

\section{The blood cells}

Mammalian hematopoiesis gives rise to long-term reconstituting HSCs that, in turn, generate short-term repopulating HSCs (Eaves et al. 2001). From these stem cells a number of more restricted progenitors emerge that give rise to all differentiated blood cells in adult circulation, such as lymphoid, myeloid, and erythroid cells (Akashi 2005). Each of these progenitors can be distinguished by a subset of cell surface markers. Development of the initial definitive HSC requires Runx-1 (North et al. 2002), and its expression later continues in differentiating myeloid and lymphoid cells (North et al. 2004). Later inactivation of Runxl within the bone marrow is not essential for adult hematopoiesis, but it does affect maturation of lymphocytes and platelets (Growney et al. 2005). The stem cell population and intermediate progenitor classes have not yet been fully defined in zebrafish, although it is clear that all myeloid and lymphoid cell types present in adult circulation are represented, as in mammals (de Jong and Zon 2005).
There is evidence for the presence of a HSC type within the kidney progenitors that is distinguished by cell size and granularity, and is capable of repopulating bloodless mutants (Traver et al. 2003). In Drosophila, the hematopoietic lineages are not as diverse as in vertebrates. All hemocytes seen are of the more ancient myeloid lineage. While there are no erythroid and lymphoid cell types, hemocytes with myeloid macrophage properties are represented (Evans et al. 2007; Williams 2007). These hemocytes then remain in circulation through larval development and in adults, where they are involved in immunity, wound repair, and apoptosis/phagocytosis /Cherry and Silverman 2006; Jiravanichpaisal et al. 2006; Lemaitre and Hoffmann 2007; Williams 2007). The blood cell types in Drosophila can be classified into three major classes. Plasmatocytes are phagocytic macrophagelike cells that comprise $>90 \%$ of the circulating population of hemocytes in wild-type larvae. Crystal cells possess paracrystalline inclusions of prophenoloxidase similar in its melanization function to the vertebrate Tyrosinase, while lamellocytes engulf larger particles of infection. Lamellocytes and crystal cells number $<5 \%$ of the total population of blood cells. A number of signaling pathways and transcription factors are conserved between the vertebrate and the Drosophila hematopoietic systems, affording the opportunity to use the powerful genetic technologies in Drosophila for unraveling developmental details of hematopoiesis (Evans and Banerjee 2003; Evans et al. 2003, 2007). In this review, we restrict our discussion to the development and maintenance of stem cells by niches defined in the murine, zebrafish, and Drosophila hematopoietic systems (Fig. 6).

\section{Phases of hematopoiesis}

In most vertebrate embryos, hematopoiesis occurs in sequential waves, often termed primitive and definitive (Cumano and Godin 2007). In mammals and in zebrafish, primitive hematopoiesis gives rise to transient populations of progenitors that differentiate into erythrocytes and macrophages (de Jong and Zon 2005; Cumano and Godin 2007). Subsequently, definitive hematopoiesis gives rise to HSCs, which generate the full range of blood cell types in the later embryo and throughout adulthood (Cumano and Godin 2007). In Drosophila as well, hematopoiesis occurs in two phases: one originating from the anterior head mesoderm giving rise to an early set of blood cells in the embryo, while additional definitive blood cell production takes place in the larval lymph gland, which contributes to the adult (Holz et al. 2003).

\section{Sites of transient embryonic hematopoiesis}

Both zebrafish and Drosophila share intraembryonic sites of early blood formation, particularly from head mesoderm. In zebrafish, expression of the Ets transcription factor PU.1 at around the 10-somite stage identified that primitive macrophages emerge from the anterior lateral mesoderm (ALM) adjacent to the midbrain 




Figure 6. Synopsis of hematopoiesis in Drosophila, zebrafish, and the mouse. A1-A5 schematically illustrate the stages of hematopoiesis. Subdomain of mesoderm (A1) is specified as lateral (lateral plate) mesoderm (A2). (A3) Progenitors of blood vessels and blood cells (hemangioblasts) arise within the lateral mesoderm. (A4) Hemangioblasts migrate throughout the embryo and differentiate into angioblasts that give rise to the vascular system and HSCs. (A5) HSCs populate hematopoietic organs and produce blood cells. Cartoons $B-D$ illustrate hematopoiesis in Drosophila. (B) Lateral view (top) and cross-section (bottom) of post-gastrula embryo, corresponding to the stage shown in $A 3$. Hemangioblasts are specified within the anterior (thoracic) segments of the cardiogenic mesoderm that forms part of the lateral mesoderm. The head mesoderm produces a set of early differentiating (embryonic) blood cells that spread out through the embryo and fill the hemolymph of the larva. (C) Lateral view (top) and cross-section (bottom) of the late embryo, corresponding to the stage shown in A4. Hemangioblasts have differentiated into the dorsal vessel and hematopoietic lymph gland. Early embryonic blood cells have spread throughout the embryo. $(D)$ Detail of the larval lymph gland, the site of production of the adult blood cells. The lymph gland has differentiated into the PSC that acts as the niche, blood stem-like cells (medullary zone), and maturing blood cells (cortical zone). PSC cells send long processes into the medullary zone (shown in inset) that may act to provide signals for maintaining the medullary zone. $E-I$ illustrate hematopoiesis in the zebrafish and mouse. (E) Mid-stage (five somites) zebrafish embryo in the lateral view (top) and cross-section (bottom). Hemangioblasts populate the lateral edge of the mesoderm; one distinguishes between anterior lateral mesoderm (ALM) and posterior lateral mesoderm (PLM). (F) Lateral view of a late zebrafish embryo. Hemangioblasts of the ALM and PLM have migrated dorsally and form the interstitial cell mass located underneath the notochord. Cells of the interstitial cell mass form the early vascular system (aorta, cardinal veins) of the embryo; they also produce blood stem cells. The earliest blood stem cells produce so-called primitive blood cells (macrophages, erythrocytes) that are found only during embryonic and larval stages. Other cells of the interstitial cell mass are set aside as definitive HSCs that spread through the circulation and populate hematopoietic organs, such as the kidney. $(G)$ Lateral view (right) and cross-section (left) of the gastrulating mouse embryo. Hemangioblasts are specified within the mesoderm that ingresses through the primitive streak. Angioblasts forming the yolk sac vascular bed and progenitors of primitive blood cells arising in the yolk sac are born during this migration; they form the so-called blood band and endothelial plexus of the yolk sac. $(H)$ Lateral view (right) and cross-section of the late embryo. Cells of the lateral plate mesoderm have migrated dorsally and formed the primordia of the embryonic kidney (mesonephros), aorta and other blood vessels, and gonad (genital ridge). Interspersed into the AGM mesoderm are HSCs of definitive hematopoiesis; such cells, recognized by the expression of specific markers (e.g., Runx1) can be observed to split from the endothelium lining the aorta (shown in inset). HSCs can also be observed in the placenta. $(I)$ HSCs populate the bone marrow of adult mice. They undergo symmetric and asymmetric divisions, thereby renewing their own number and producing populations of rapidly proliferating blood progenitors that differentiate into blood cells. 
(Lieschke et al. 2002). Live imaging confirmed the migration of these cells into the yolk sac (Zhang and Rodaway 2007). In Drosophila, the initial wave of hemocyte differentiation also occurs in the head mesoderm region during the early embryonic period (Tepass et al. 1994). Two transcription factors play key roles in this process. Glial cells missing $(\mathrm{Gcm})$ is required for the specification of plasmatocytes (Lebestky et al. 2000; Bataille et al. 2005), and the Runx-like transcription factor Lozenge (Lz) is necessary for crystal cell development (Lebestky et al. 2000). The involvement of the transcription factor $\mathrm{Gcm}$ in the specification of both glial and macrophagelike blood cells in Drosophila suggests the possibility of shared functional properties. In mammals, microglia serve phagocytic functions in the brain similar to those of macrophages in the periphery (Chan et al. 2007). Perhaps the primitive macrophages in Drosophila arising from the head mesoderm are akin to the monocyte-like mammalian microglial population, which originates independently of the bone marrow-derived monocyte precursor (Chan et al. 2007).

The first hematopoietic organ in both mouse and human is the yolk sac, which has a well-established role in the generation of transient hematopoietic populations for the immediate needs of the embryo, including primitive red cells required for oxygen transport (Palis et al. 1999), macrophages for tissue remodeling and defense (Bertrand et al. 2005), and unique primitive megakaryocytes (Tober et al. 2007). After this so-called primitive hematopoiesis, a burst of production of multipotential myeloerythroid progenitors occurs (Mikkola and Orkin 2006). They are the first hematopoietic cells that seed the liver, where they give rise to definitive red cells and myeloid cells. The literature on the exact nature of these cells and their role has been controversial (Mikkola and Orkin 2006). These progenitors are classified as definitive, as their erythroid progeny express adult type globins. However, they should perhaps be named transient or short-term definitive progenitors since their ability to contribute to adult hematopoiesis has been doubtful. Both direct transplantation into adult recipients and explant cultures of early yolk sac tissues have failed to verify de novo HSC generation in the yolk sac. In contrast, other studies have suggested that yolk sac cells may contribute to adult hematopoiesis if injected into fetal environments. More recently, an estrogen-inducible mouse model was utilized to permanently label Runx1-expressing cells prior to circulation, and contribution of the labeled cells to adult hematopoiesis led to the conclusion that HSC generation starts in the yolk sac (Samokhvalov et al. 2007). It is therefore possible that the negative results in adult transplantation assays reflect immaturity of the nascent yolk sac hematopoietic cells, which may be yet unable to engraft and survive in adult niches. Alternatively, these cells may represent a transient precursor population that shares only some characteristics with adult-type definitive hematopoietic cells, but do not contribute to adult hematopoiesis. These scenarios are not mutually exclusive; it is plausible that the yolk sac generates three waves of hemato- poietic cells: primitive hematopoietic cells, transient definitive progenitors, and definitive HSCs. Although it is yet unclear whether all the waves of hematopoiesis in the yolk sac have a common ancestry, it has been shown that mesodermal cells that migrate through the primitive streak have both primitive and definitive hematopoietic as well as endothelial potential, suggesting that they represent hemangioblasts that give rise to yolk sac hematopoietic cells (Huber et al. 2004).

Unlike the extraembryonic origin of mammalian primitive hematopoiesis, the first events of zebrafish hematopoiesis occur within the embryo proper. Expression of the blood cell-specific transcription factor GATA-1 allows visualization of the dynamic pattern of blood cell progenitor migration (Detrich et al. 1995). At the twosomite stage, two stripes of progenitors that flank the paraxial or posterior/caudal lateral plate mesoderm converge at the midline and fuse completely by the 24 -somite stage forming the intermediate cell mass (ICM), located ventral to the notochord (Al-Adhami and Kunz 1977). This process can be visualized in vivo using time lapse microscopy, as these cells move through the somites (Zhang and Rodaway 2007). The first intraembryonic blood forms as proerythroblasts and endothelial cells differentiate from these stripes by the end of the 24-somite stage. The cells of the ICM then migrate anteriorly and enter the yolk sac, where erythroblasts continue to mature. By $24 \mathrm{~h}$, these erythroblasts are released once the common cardinal vein and ducts of Cuvier have formed and circulation is established. The ICM also forms the major vessels of the trunk: the dorsal aorta and the posterior cardinal vein (PCV) (Al-Adhami and Kunz 1977).

\section{Sites of emergence of definitive HSCs}

The embryo proper has been considered to be the major source of HSCs in mammals (Dzierzak 2002). In mice, the aorta-gonad-mesonephros (AGM) region, which is the primary intraembryonic hemogenic territory, harbors adult-type HSCs over a short period during midgestation. During this time, clusters that consist of Runx1expressing HSCs can be visualized budding into the lumen from the ventral side of the dorsal aorta, suggesting that they originate in situ (Jaffredo et al. 2005). Of note, the dorsal aorta is not the only hemogenic artery: The emergence of putative HSCs has also been documented from umbilical and vitelline arteries that connect the dorsal aorta to the placenta and yolk sac (Bruijn et al. 2000). However, in spite of the intimate association of HSC generation and arterial vasculature, it is yet unclear whether definitive HSCs are specified directly from a hemogenic endothelial precursor. An alternative model suggests that HSCs arise from a mesodermal/hemangioblast precursor that is specified to a hematopoietic fate in the subvascular mesenchyme and migrates through the vascular wall to enter circulation (Bertrand et al. 2005).

Similar to mammalian definitive hematopoiesis, the site of formation of the first definitive HSCs in zebrafish 
is the AGM. The AGM equivalent in zebrafish is found adjacent to the ventral wall of the dorsal (DA). The earliest Scl-positive definitive hematopoietic progenitors arise between the floor of the DA and the roof of the PCV at $26-30 \mathrm{~h}$ (Zhang and Rodaway 2007). These cells subsequently migrate to the kidney, the adult hematopoietic organ in zebrafish, by $5 \mathrm{~d}$ post-fertilization (dpf). During embryogenesis, hemangiopoietic capacity of the ICM switches to the AGM region within the first few days of development as reflected by decreasing expression of Gatal in the ICM while expression of c-Myb and Runx1 increases in the AGM and loss of Runxl function causes elimination of the trunk hematopoietic clusters (Kalev-Zylinska et al. 2002; Burns et al. 2005; Murayama et al. 2006). Furthermore, laser activation of caged fluorescein in the region between the DA and PCV at $2 \mathrm{dpf}$ results in labeling of cells in the thymus and pronephros at $5 \mathrm{dpf}$ (Murayama et al. 2006). Additional data suggests that cells from the AGM also seed the ventral vein on their way to the kidney (Zhang and Rodaway 2007).

The second phase of Drosophila hematopoiesis initiates in an organ called the lymph gland. The origin of the lymph gland tissue in the embryo bears remarkable resemblance to AGM hematopoiesis in zebrafish and mouse (Evans et al. 2007). The origin of the mammalian AGM can be traced to the progenitors of the lateral plate mesoderm. FGF, along with BMP, is expressed in both lateral plate mesoderm and adjacent endoderm, and are required to separate the cardiac mesoderm from the AGM (Nishikawa et al. 2001). Similarly in Drosophila, FGF, BMP, and Wnt/Wg signaling are sequentially involved in specifying the cardiogenic mesoderm from the dorsal mesoderm of the embryo (Mandal et al. 2004). The cardiogenic mesoderm has been likened to the vertebrate AGM mesenchyme because both structures give rise not only to blood but also to endothelial cells and nephrocytes (Mandal et al. 2004). From the cardiogenic mesoderm, Notch signaling regulates the switch between vascular and blood progenitors, eventually giving rise to a lymph gland, a heart tube, and nephrocyte-like pericardial cells, similar to the aorta, blood, and mesonephros in vertebrates (Mandal et al. 2004).

Unlike the vertebrate AGM, the Drosophila lymph gland is retained throughout larval development as a site for definitive hematopoiesis. The lymph gland is located in the dorsal aspect of the larva, in association with the Drosophila heart, the dorsal vessel. It is composed of two primary lobes and several secondary lobes. The primary lobe is structured into an outer shell, termed the cortical zone, that harbors maturing hemocytes, and a central core, named the medullary zone, that contains immature stem-like progenitors (Jung et al. 2005). A small cluster of cells expressing several signaling molecules is located adjacent to the medullary zone precursors and has been termed the posterior signaling center (PSC) (Lebestky et al. 2003). The cells of the PSC serve as the hematopoietic niche (Mandal et al. 2007)

In addition to the yolk sac and AGM, additional hematopoietic sites in vertebrate embryos were first identified in birds. Initial studies using the quail-chick chi- mera assay first described the presence of definitive hematopoietic cells that contribute to adult hematopoiesis within the allantois region (Caprioli et al. 1998). In mammals, the allantois gives rise to the mesodermal components of the placenta. Strikingly, a large pool of HSCs are present in midgestation mouse placenta, suggesting that the placenta is yet another important hematopoietic organ (Alvarez-Silva et al. 2003; Gekas et al. 2005; Ottersbach and Dzierzak 2005). HSC activity in the placenta starts concomitantly with the AGM and yolk sac, but exceeds in numbers (15-fold more HSCs) and duration that in the other two sites. As the placenta is directly upstream of the fetal liver in fetal circulation, it is likely to be a major source of definitive HSCs that seed the liver. Recent analysis of $\mathrm{Ncx}^{-/-}$mutant mice showed that definitive HSCs emerge de novo in placental large vessels, independent of the contribution from circulating cells (K. Rhodes and H.K.A. Mikkola, unpubl.). Furthermore, the placental vascular labyrinth may provide a unique microenvironment for HSC maturation and expansion, without promoting immediate lineage differentiation. These data propose the placenta as an important hematopoietic organ that is capable of both generating and temporarily maintaining a large pool of definitive HSCs.

\section{Sites of HSC expansion}

After progenitors and HSCs emerge from hemogenic sites they circulate to the fetal liver, which serves as the main hematopoietic organ for expansion and differentiation during mid-late gestation in mice. In mice, the liver is first seeded by yolk sac-derived progenitors, followed by HSC seeding from the AGM, the placenta, and perhaps the yolk sac (Cumano and Godin 2007). A recent cell tracing analysis using an inducible system linked to the runx1 promoter confirmed that precursors labeled prior to circulation eventually migrate to the fetal liver for expansion, and ultimately colonize the thymus and bone marrow once these organs develop (Samokhvalov et al. 2007). As the yolk sac is the earliest hematopoietic site with abundant Runxl expression, it was proposed that these cells arise from the yolk sac. Labeled cells primarily contribute to circulating cells in the embryo, and eventually these stem cells will contribute to $10 \%$ of HSCs present in adult bone marrow and $\sim 10 \%$ of cells in adult circulation (Samokhvalov et al. 2007). A similar process in zebrafish allows early primitive progenitors to give rise to circulating precursors that eventually seed the definitive hematopoietic organ, the kidney, and contribute to circulating cells of the embryo (Murayama et al. 2006; Zhang and Rodaway 2007).

In addition to supporting HSC expansion, the liver is also the main site for hematopoietic differentiation in the fetus, providing a microenvironment both for myeloerythroid and B-lymphoid differentiation (Mikkola and Orkin 2006). Although the exact cellular niches that support HSC self-renewal or differentiation in fetal liver have not been defined, both endothelial and stromal cells, and perhaps developing hepatocytes, likely provide 
cues into the hematopoietic microenvironment. Gene expression studies on liver-derived cell lines identified proteins such as IGF2 and angiopoietin-like factors that are associated with HSC supportive properties (Zhang and Lodish 2004; Zhang et al. 2006).

In a manner analogous to the mammalian liver, the intermediate HSC expansion site in zebrafish is the caudal hematopoietic tissue (CHT). After exiting the AGM region but before reaching the pronephros the hematopoietic progenitors migrate to this tissue, located between the caudal artery and veins (Jin et al. 2007). The CHT likely provides a transitional niche to support definitive HSC expansion and maturation in the zebrafish (Murayama et al. 2006).

\section{Adult hematopoietic niches}

The bone marrow is the site of adult hematopoiesis and HSC maintenance in mammals (Mikkola and Orkin 2006). Transplantation assays have shown that HSCs start to shift from the fetal liver to the bone marrow during late-gestation/first days of postnatal life in mice (Gothert et al. 2005; Bowie et al. 2006). The properties of HSCs change after they engraft in the bone marrow as they transition from active cycling to quiescence. This transition is intrinsically programmed and occurs at a precise time point between 3 and 4 wk of postnatal life in mice (Bowie et al. 2007). Interestingly, Sox17 has been recently identified as a factor that is important for the self-renewal of fetal and early postnatal HSCs in the bone marrow, whereas it becomes unimportant after the first weeks of life (Kim et al. 2007). This study documents for the first time a transcription factor that is unique for self-renewal of cycling HSCs during late fetal/ early postnatal life but not in the adult, implying that the molecular requirements for self-renewal are different during development. Reverse examples involving mutations in which defects in bone marrow hematopoiesis can be observed without affecting the fetal liver HSC pool are fairly common. Specifically, transcriptional repressors Tel (Hock et al. 2004b), Gfil (Hock et al. 2004a), and Bmil (Park et al. 2003), have been implicated as intrinsic regulators of HSC self-renewal or survival during postnatal life without having an effect on embryonic self-renewal. Specific microenvironment-dependent requirements such as that of the calcium receptor has also been established in the bone marrow without it having a role in the liver, suggesting that HSCs specifically sense calcium levels to establish long-term residence in the bone marrow (Adams et al. 2006).

In zebrafish, adult hematopoiesis and HSC maintenance continue in the kidney. Recent studies have ascertained that hematopoietic cells isolated from the adult kidney are quiescent and express stem cell markers (Tsinkalovsky et al. 2007). A number of potential signaling molecules have been identified that affect stem cell maintenance and differentiation in zebrafish. These include BMP (Moser et al. 2007), JAK-STAT (Ma et al. 2007), FGF (Songhet et al. 2007), Sonic hedgehog (Gering and Patient 2005), Notch (Burns et al. 2005), and VEGF
(Gering and Patient 2005), but what remains unclear is whether these molecular pathways act at the level of the stem cell or are required in more downstream progenitors. Transcription factors important in mammalian hematopoiesis such as Hox genes (Davidson and Zon 2006), SCL (Qian et al. 2007), Runx-1 (Kalev-Zylinska et al. 2002), and c-Myb (Thompson et al. 1998) have all also been implicated in zebrafish hematopoietic maintenance.

In Drosophila, the lymph gland persists as the hematopoietic organ through larval stages and disintegrates during metamorphosis, releasing mature blood cells into the circulation. No sites of de novo hematopoiesis have been identified to date in the adult fruit fly, although such sites have been reported in other invertebrates (Soderhall et al. 2003), suggesting that further analysis of this issue is warranted. The lymph gland presents an attractive system for genetically investigating the interaction between a niche (called the PSC), a set of stemlike progenitors belonging to the medullary zone, and a group of differentiated cells belonging to the cortical zone that arise from the stem-like progenitors of the medullary zone. The medullary zone progenitors are mitotically quiescent, retain the Histone H2B-GFP label (J.L. Marshall and U. Banerjee, unpubl.), give rise to all blood cell types, do not express differentiation markers, and are maintained in a niche-dependent manner (Mandal et al. 2007). In all these respects these cells fulfill the criteria of being stem cells. However, definitive experiments to show that such cells are maintained through life or are capable of reconstituting the hematopoietic repertoire upon transplantation remains to be shown.

\section{Molecular interactions at the hematopoietic niche}

Osteoblast-specific loss of BMP-receptor 1 in mouse causes an increase in the number of osteoblasts and also a concomitant growth in the HSC pool (Zhang et al. 2003). Conversely, targeting the osteoblasts with a suicide-gene causes metabolic death of the osteoblasts and also perturbs hematopoiesis (Visnjic et al. 2004). Likewise, stimulation of the parathyroid receptor by overexpression of PTH-PTHRP results in an increase in both the trabecular bone and the number of HSCs (Calvi et al. 2003). Taken together these results identified the osteoblast as an integral component of the hematopoietic niche. It has been proposed that adhesive contacts through $\mathrm{N}$-cadherin and Tie2/angiopoietin interactions hold the HSCs anchored to the endosteal niche promoting HSC quiescence (Arai et al. 2004). C-myc has been shown to be an important cell intrinsic regulator required for HSC homeostasis regulating the release of HSCs from the quiescence-promoting niche. Upon conditional ablation of c-myc in bone marrow HSCs, these stem cells are unable to differentiate as they increase adhesion molecules on their surface and remain anchored to the niche that retains them in a quiescent, undifferentiated state (Wilson et al. 2004). Although the osteoblast endosteal niche of the mouse bone marrow is so far the best characterized hematopoietic niche, the 
majority of the HSCs that engraft in transplantation assays actually localize in perivascular spaces, in contact with sinusoidal venous endothelium (Kiel et al. 2005), leading to the speculation that these surfaces may provide additional niche-like interactions for the maintenance of adult HSCs.

Despite the phylogenetic differences between mammals and invertebrates, it has been remarkable to find similar strategic mechanisms utilized and conserved between vertebrate and Drosophila hematopoietic nichestem cell interactions. The lymph gland primordium in Drosophila is formed by the coalescence of three paired clusters of cells that arise within the embryonic cardiogenic mesoderm. During late embryogenesis, expression of the homeodomain protein Antennapedia (Antp) is restricted to a fraction of these cells at the posterior boundary of the lymph gland (Mandal et al. 2007). This cluster of cells comprises the PSC, while the remaining cells will give rise to hemocytes. The Antennapedia-positive cells are also positive for the B-cell factor-like transcription factor Collier (Crozatier et al. 2004), and the signaling molecules Serrate (Lebestky et al. 2003), Hedgehog (Mandal et al. 2007), and Unpaired3 (Jung et al. 2005; Krzemien et al. 2007). At the third larval instar, genetic manipulations that increase the number of PSC cells cause a concomitant increase in the number of stem-like progenitors. On the other hand, ablation of the PSC causes loss of the medullary zone progenitors due to premature differentiation. This intimate relationship between niche size and stem cell number is similar to that observed in the BMP receptor-containing osteoblasts of the adult mouse bone marrow as described above. In Drosophila, stem cell maintenance is mediated by a Hedgehog (Hh) signal emanating from the PSC and sensed by the stem-like cells of the medullary zone (Mandal et al. 2007). The Hh-expressing cells of the PSC extend fine projections that interdigitate between the progenitors of the medullary zone (Mandal et al. 2007). The Hedgehog (Hh)/Sonic hedgehog (Shh) signaling pathway appears to represent a conserved universal molecular mechanism for maintaining stem cells in many niche systems. In zebrafish, Shh is required for the onset of definitive hematopoiesis (Gering and Patient 2005), while in the mouse, Shh mediates HSC self-renewal (Trowbridge et al. 2006). Similarly, Hh signaling is required for stem cell self-renewal and maintenance in other stem cell niches, such as the Drosophila ovary somatic stem cell (Zhang and Kalderon 2001), the mouse intestinal epithelium (Ramalho-Santos et al. 2000), neural (Lai et al. 2003), and hair follicle niches (Gritli-Linde et al. 2007). In addition to Hh mutants, loss of medullary zone maintenance is also observed in mutants that eliminate the STAT protein (Krzemien et al. 2007), suggesting a role of the JAK-STAT pathway in the nicheprogenitor interaction during Drosophila hematopoiesis.

Human leukemias have frequently been called a stem cell disease (Passegue et al. 2003), and the so-called leukemia stem cell (LSC) (Wang and Dick 2005) represents an aberration in the balance between self renewal and differentiation that all normal stem cells possess. In many human leukemias the LSC posseses stem-like properties, such as quiescence and the dependence on a niche. Examples of myeloproliferative disease due solely to a defect in the microenvironment of a stem cell have also been described (Walkley et al. 2007a). It is therefore of critical importance that the complete molecular basis for the interaction between the stem cell and its niche becomes available. While the mouse and human studies will continue to provide results with the most immediate relevance, the similarities with zebrafish and Drosophila hematopoiesis highlighted in this review suggest that these simpler systems will allow the power of fine genetic dissection to be extended to hematopoiesis.

\section{Acknowledgments}

We thank Cory Evans for critical reading of the manuscript. Due to the vast literature available on this topic and the space limitations, we apologize to our colleagues whose work has been omitted. This work was supported by grant K08HL087026 to J.M., R01HL067395 to U.B., and R21DK069659 to H.M.

\section{References}

Adams, G.B., Chabner, K.T., Alley, I.R., Olson, D.P., Szczepiorkowski, Z.M., Poznansky, M.C., Kos, C.H., Pollak, M.R., Brown, E.M., and Scadden, D.T. 2006. Stem cell engraftment at the endosteal niche is specified by the calcium-sensing receptor. Nature 439: 599-603.

Akashi, K. 2005. Lineage promiscuity and plasticity in hematopoietic development. Ann. N. Y. Acad. Sci. 1044: 125-131.

Al-Adhami, M. and Kunz, Y. 1977. Ontogenesis of hematopoietic sites in Brachydanio rerio (Hamilton-Buchanan) (Teleostei). Dev. Growth Differ. 19: 171-179.

Albertson, D.G., Sulston, J.E., and White, J.G. 1978. Cell cycling and DNA replication in a mutant blocked in cell division in the nematode Caenorhabditis elegans. Dev. Biol. 63: 165178.

Alvarez-Silva, M., Belo-Diabangouaya, P., Salaun, J., and Dieterlen-Lievre, F. 2003. Mouse placenta is a major hematopoietic organ. Development 130: 5437-5444.

Arai, F., Hirao, A., Ohmura, M., Sato, H., Matsuoka, S., Takubo, K., Ito, K., Koh, G.Y., and Suda, T. 2004. Tie2/angiopoietin-1 signaling regulates hematopoietic stem cell quiescence in the bone marrow niche. Cell 118: 149-161.

Arbouzova, N.I. and Zeidler, M.P. 2006. JAK/STAT signalling in Drosophila: Insights into conserved regulatory and cellular functions. Development 133: 2605-2616.

Austin, J. and Kimble, J. 1987. glp-1 Is required in the germ line for regulation of the decision between mitosis and meiosis in C. elegans. Cell 51: 589-599.

Bataille, L., Auge, B., Ferjoux, G., Haenlin, M., and Waltzer, L. 2005. Resolving embryonic blood cell fate choice in Drosophila: Interplay of GCM and RUNX factors. Development 132: 4635-4644.

Beckmann, J., Scheitza, S., Wernet, P., Fischer, J.C., and Giebel, B. 2007. Asymmetric cell division within the human hematopoietic stem and progenitor cell compartment: Identification of asymmetrically segregating proteins. Blood 109: 5494-5501.

Bendall, S.C., Stewart, M.H., Menendez, P., George, D., Vijayaragavan, K., Werbowetski-Ogilvie, T., Ramos-Mejia, V., Rouleau, A., Yang, J., Bosse, M., et al. 2007. IGF and FGF cooperatively establish the regulatory stem cell niche of plu- 
ripotent human cells in vitro. Nature 448: 1015-1021.

Bertrand, J.Y., Jalil, A., Klaine, M., Jung, S., Cumano, A., and Godin, I. 2005. Three pathways to mature macrophages in the early mouse yolk sac. Blood 106: 3004-3011.

Betschinger, J. and Knoblich, J.A. 2004. Dare to be different: Asymmetric cell division in Drosophila, C. elegans and vertebrates. Curr. Biol. 14: R674-R685. doi: 10.1016/ j.cub.2004.08.017.

Bhattacharya, D., Rossi, D.J., Bryder, D., and Weissman, I.L. 2006. Purified hematopoietic stem cell engraftment of rare niches corrects severe lymphoid deficiencies without host conditioning. J. Exp. Med. 203: 73-85.

Biswas, A. and Hutchins, R. 2007. Embryonic stem cells. Stem Cells Dev. 16: 213-222.

Bowie, M.B., McKnight, K.D., Kent, D.G., McCaffrey, L., Hoodless, P.A., and Eaves, C.J. 2006. Hematopoietic stem cells proliferate until after birth and show a reversible phase-specific engraftment defect. J. Clin. Invest. 116: 2808-2816.

Bowie, M.B., Kent, D.G., Dykstra, B., McKnight, K.D., McCaffrey, L., Hoodless, P.A., and Eaves, C.J. 2007. Identification of a new intrinsically timed developmental checkpoint that reprograms key hematopoietic stem cell properties. Proc. Natl. Acad. Sci. 104: 5878-5882.

Brinster, R.L. 2002. Germline stem cell transplantation and transgenesis. Science 296: 2174-2176.

Bruijn, M.F.T.R.D., Speck, N., Peeters, M.E., and Dzierzak, E. 2000. Definitive hematopoietic stem cells first develop within the major arterial regions of the mouse embryo. EMBO J. 19: 2465-2474.

Burns, C.E., Traver, D., Mayhall, E., Shepard, J.L., and Zon, L.I. 2005. Hematopoietic stem cell fate is established by the Notch-Runx pathway. Genes \& Dev. 19: 2331-2342.

Calvi, L.M., Adams, G.B., Weibrecht, K.W., Weber, J.M., Olson, D.P., Knight, M.C., Martin, R.P., Schipani, E., Divieti, P., Bringhurst, F.R., et al. 2003. Osteoblastic cells regulate the haematopoietic stem cell niche. Nature 425: 841-846.

Caprioli, A., Jaffredo, T., Gautier, R., Dubourg, C., and Dieterlen-Lievre, F. 1998. Blood-borne seeding by hematopoietic and endothelial precursors from the allantois. Proc. Natl. Acad. Sci. 95: 1641-1646.

Cayre, M., Scotto-Lomassese, S., Malaterre, J., Strambi, C., and Strambi, A. 2007. Understanding the regulation and function of adult neurogenesis: Contribution from an insect model, the house cricket. Chem. Senses 32: 385-395.

Chan, W.Y., Kohsaka, S., and Rezaie, P. 2007. The origin and cell lineage of microglia-New concepts. Brain Res. Brain Res. Rev. 53: 344-354.

Cherry, S. and Silverman, N. 2006. Host-pathogen interactions in Drosophila: New tricks from an old friend. Nat. Immunol. 7: 911-917.

Cox, D.N., Chao, A., and Lin, H. 2000. piwi encodes a nucleoplasmic factor whose activity modulates the number and division rate of germline stem cells. Development 127: 503514.

Crittenden, S.L., Leonhard, K.A., Byrd, D.T., and Kimble, J. 2006. Cellular analyses of the mitotic region in the Caenorhabditis elegans adult germ line. Mol. Biol. Cell 17: 3051-3061.

Crozatier, M., Ubeda, J.-M., Vincent, A., and Meister, M. 2004. Cellular immune response to parasitization in drosophila requires the EBF orthologue collier. PLOS Biol. 2: e196. doi: 10.1371/journal.pbio.0020196.

Cumano, A. and Godin, I. 2007. Ontogeny of the hematopoietic system. Annu. Rev. Immunol. 25: 745-785.

Davidson, A.J. and Zon, L.I. 2006. The caudal-related homeobox genes cdxla and cdx4 act redundantly to regulate hox gene expression and the formation of putative hematopoietic stem cells during zebrafish embryogenesis. Dev. Biol. 292: 506-518.

de Jong, J.L.O. and Zon, L.I. 2005. Use of the zebrafish system to study primitive and definitive hematopoiesis. Annu. Rev. Genet. 39: 481-501.

Deng, W. and Lin, H. 1997. Spectrosomes and fusomes anchor mitotic spindles during asymmetric germ cell divisions and facilitate the formation of a polarized microtubule array for oocyte specification in Drosophila. Dev. Biol. 189: 79-94.

Detrich, H., Kieran, M., Chan, F., Barone, L., Yee, K., Rundstadler, J., Pratt, S., Ransom, D., and Zon, L. 1995. Intraembryonic hematopoietic cell migration during vertebrate development. Proc. Natl. Acad. Sci. 92: 10713-10717.

Díaz-Flores, L., Madrid, J.F., Gutiérrez, R., Varela, H., Valladares, F., Alvarez-Argüelles, H., and Díaz-Flores, L. 2006. Adult stem and transit-amplifying cell location. Histol. Histopathol. 21: 995-1027.

Dumstrei, K., Wang, F., and Hartenstein, V. 2003. Role of DEcadherin in neuroblast proliferation, neural morphogenesis, and axon tract formation in Drosophila larval brain development. J. Neurosci. 23: 3325-3335.

Dzierzak, E. 2002. Hematopoietic stem cells and their precursors: Developmental diversity and lineage relationships. Immunol. Rev. 187: 126-138.

Eaves, C., Glimm, H., Eisterer, W., Audet, J., Maguer-Satta, V., and Pireta, J. 2001. Characterization of human hematopoietic cells with short-lived in vivo repopulating activity. Ann. N. Y. Acad. Sci. 938: 63-71.

Ema, H., Takano, H., Sudo, K., and Nakauchi, H. 2000. In vitro self-renewal division of hematopoietic stem cells. J. Exp. Med. 192: 1281-1288.

Evans, C.J. and Banerjee, U. 2003. Transcriptional regulation of hematopoiesis in Drosophila. Blood Cells Mol. Dis. 30: 223228.

Evans, C.J., Hartenstein, V., and Banerjee, U. 2003. Thicker than blood: Conserved mechanisms in Drosophila and vertebrate hematopoiesis. Dev. Cell 5: 673-690.

Evans, C., Sinenko, S., Mandal, L., Martinez-Agosto, J., Hartenstein, V., and Banerjee, U. 2007. Genetic dissection of hematopoiesis using Drosophila as a model system. In Advances in developmental biology (ed. P. Wassarman), pp. 259-299. Elsevier Science, New York.

Fuller, M.T. and Spradling, A.C. 2007. Male and female Drosophila germline stem cells: Two versions of immortality. Science 316: 402-404.

Gekas, C., Dieterlen-Lievre, F., Orkin, S.H., and Mikkola, H.K. 2005. The placenta is a niche for hematopoietic stem cells. Dev. Cell 8: 365-375.

Gering, M. and Patient, R. 2005. Hedgehog signaling is required for adult blood stem cell formation in zebrafish embryos. Dev. Cell 8: 389-400.

Giebel, B., Zhang, T., Beckmann, J., Spanholtz, J., Wernet, P., Ho, A.D., and Punzel, M. 2006. Primitive human hematopoietic cells give rise to differentially specified daughter cells upon their initial cell division. Blood 107: 2146-2152.

Godt, D. and Tepass, U. 1998. Drosophila oocyte localization is mediated by differential cadherin-based adhesion. Nature 395: 387-391.

Gonzalez-Reyes, A. 2003. Stem cells, niches and cadherins: A view from Drosophila. J. Cell Sci. 116: 949-954.

Gothert, J.R., Gustin, S.E., Hall, M.A., Green, A.R., Gottgens, B., Izon, D.J., and Begley, C.G. 2005. In vivo fate-tracing studies using the Scl stem cell enhancer: Embryonic hematopoietic stem cells significantly contribute to adult hematopoiesis. Blood 105: 2724-2732. 
Gritli-Linde, A., Hallberg, K., Harfe, B.D., Reyahi, A., KanniusJanson, M., Nilsson, J., Cobourne, M.T., Sharpe, P.T., McMahon, A.P., and Linde, A. 2007. Abnormal hair development and apparent follicular transformation to mammary gland in the absence of hedgehog signaling. Dev. Cell 12: 99-112.

Growney, J.D., Shigematsu, H., Li, Z., Lee, B.H., Adelsperger, J., Rowan, R., Curley, D.P., Kutok, J.L., Akashi, K., Williams, I.R., et al. 2005. Loss of Runx1 perturbs adult hematopoiesis and is associated with a myeloproliferative phenotype. Blood 106: 494-504.

Halbleib, J.M. and Nelson, W.J. 2006. Cadherins in development: Cell adhesion, sorting, and tissue morphogenesis. Genes \& Dev. 20: 3199-3214.

Hansen, D., Schedl, T., and Gerald, P.S. 2006. The regulatory network controlling the proliferation-meiotic entry decision in the Caenorhabditis elegans germ line. In Current topics in developmental biology, pp. 185-215. Academic Press, New York.

Harrison, D.A. and Perrimon, N. 1993. Simple and efficient generation of marked clones in Drosophila. Curr. Biol. 3: 424433.

He, X.C., Zhang, J., Tong, W.-G., Tawfik, O., Ross, J., Scoville, D.H., Tian, Q., Zeng, X., He, X., Wiedemann, L.M., et al. 2004. BMP signaling inhibits intestinal stem cell self-renewal through suppression of Wnt- $\beta$-catenin signaling. Nat. Genet. 36: 1117-1121.

Hock, H., Hamblen, M.J., Rooke, H.M., Schindler, J.W., Saleque, S., Fujiwara, Y., and Orkin, S.H. 2004a. Gfi-1 restricts proliferation and preserves functional integrity of haematopoietic stem cells. Nature 431: 1002-1007.

Hock, H., Meade, E., Medeiros, S., Schindler, J.W., Valk, P.J., Fujiwara, Y., and Orkin, S.H. 2004b. Tel/Etv6 is an essential and selective regulator of adult hematopoietic stem cell survival. Genes \& Dev. 18: 2336-2341.

Holz, A., Bossinger, B., Strasser, T., Janning, W., and Klapper, R. 2003. The two origins of hemocytes in Drosophila. Development 130: 4955-4962.

Huber, T.L., Kouskoff, V., Fehling, H.J., Palis, J., and Keller, G. 2004. Haemangioblast commitment is initiated in the primitive streak of the mouse embryo. Nature 432: 625-630.

Jaffredo, T., Gautier, R., Eichmann, A., and Dieterlen-Lievre, F. 1998. Intraaortic hemopoietic cells are derived from endothelial cells during ontogeny. Development 125: 4575-4583.

Jaffredo, T., Nottingham, W., Liddiard, K., Bollerot, K., Pouget, C., and de Bruijn, M. 2005. From hemangioblast to hematopoietic stem cell: An endothelial connection? Exp. Hematol. 33: $1029-1040$.

Jin, H., Xu, J., and Wen, Z. 2007. Migratory path of definitive hematopoietic stem/progenitor cells during zebrafish development. Blood 109: 5208-5214.

Jiravanichpaisal, P., Lee, B.L., and Soderhall, K. 2006. Cell-mediated immunity in arthropods: Hematopoiesis, coagulation, melanization and opsonization. Immunobiology 211: 213236.

Jung, S.-H., Evans, C.J., Uemura, C., and Banerjee, U. 2005. The Drosophila lymph gland as a developmental model of hematopoiesis. Development 132: 2521-2533.

Kalev-Zylinska, M.L., Horsfield, J.A., Flores, M.V.C., Postlethwait, J.H., Vitas, M.R., Baas, A.M., Crosier, P.S., and Crosier, K.E. 2002. Runx1 is required for zebrafish blood and vessel development and expression of a human RUNX1CBF2T1 transgene advances a model for studies of leukemogenesis. Development 129: 2015-2030.

Kiel, M.J., Yilmaz, O.H., Iwashita, T., Yilmaz, O.H., Terhorst, C., and Morrison, S.J. 2005. SLAM family receptors distin- guish hematopoietic stem and progenitor cells and reveal endothelial niches for stem cells. Cell 121: 1109-1121.

Kim, I., Saunders, T.L., and Morrison, S.J. 2007. Sox17 dependence distinguishes the transcriptional regulation of fetal from adult hematopoietic stem cells. Cell 130: 470-483.

Kimble, J. and Crittenden, S.L. 2007. Controls of germline stem cells, entry into meiosis, and the sperm/oocyte decision in Caenorhabditis elegans. Annu. Rev. Cell Dev. Biol. 23: 405433.

Knoblich, J.A. 2001. Asymmetric cell division during animal development. Nat. Rev. Mol. Cell Biol. 2: 11-20.

Kobielak, K., Stokes, N., de la Cruz, J., Polak, L., and Fuchs, E. 2007. Loss of a quiescent niche but not follicle stem cells in the absence of bone morphogenetic protein signaling. Proc. Nat1. Acad. Sci. 104: 10063-10068.

Krause, D.S., Theise, N.D., Collector, M.I., Henegariu, O., Hwang, S., Gardner, R., Neutzel, S., and Sharkis, S.J. 2001. Multi-organ, multi-lineage engraftment by a single bone marrow-derived stem cell. Cell 105: 369-377.

Krzemien, J., Dubois, L., Makki, R., Meister, M., Vincent, A., and Crozatier, M. 2007. Control of blood cell homeostasis in Drosophila larvae by the posterior signalling centre. Nature 446: 325-328.

Lai, K., Kaspar, B.K., Gage, F.H., and Schaffer, D.V. 2003. Sonic hedgehog regulates adult neural progenitor proliferation in vitro and in vivo. Nat. Neurosci. 6: 21-27.

Lapidot, T., Pflumio, F., Doedens, M., Murdoch, B., Williams, D.E., and Dick, J.E. 1992. Cytokine stimulation of multilineage hematopoiesis from immature human cells engrafted in SCID mice. Science 255: 1137-1141.

Lebestky, T., Chang, T., Hartenstein, V., and Banerjee, U. 2000. Specification of Drosophila hematopoietic lineage by conserved transcription factors. Science 288: 146-149.

Lebestky, T., Jung, S.-H., and Banerjee, U. 2003. A Serrate-expressing signaling center controls Drosophila hematopoiesis. Genes \& Dev. 17: 348-353.

Leedham, S.J., Brittan, M., McDonald, S.A.C., and Wright, N.A. 2005. Intestinal stem cells. J. Cell. Mol. Med. 9: 11-24.

Lemaitre, B. and Hoffmann, J. 2007. The host defense of Drosophila melanogaster. Annu. Rev. Immunol. 25: 697-743.

Lieschke, G.J., Oates, A.C., Paw, B.H., Thompson, M.A., Hall, N.E., Ward, A.C., Ho, R.K., Zon, L.I., and Layton, J.E. 2002. Zebrafish SPI-1 (PU.1) marks a site of myeloid development independent of primitive erythropoiesis: Implications for axial patterning. Dev. Biol. 246: 274-295.

Lin, H. and Spradling, A.C. 1995. Fusome asymmetry and oocyte determination in Drosophila. Dev. Genet. 16: 6-12.

Lowry, W.E., Blanpain, C., Nowak, J.A., Guasch, G., Lewis, L., and Fuchs, E. 2005. Defining the impact of $\beta$-catenin/Tcf transactivation on epithelial stem cells. Genes \& Dev. 19: 1596-1611.

Ma, A.C.H., Ward, A.C., Liang, R., and Leung, A.Y. 2007. The role of jak2a in zebrafish hematopoiesis. Blood 110: 1824 1830.

Maherali, N., Sridharan, R., Xie, W., Utikal, J., Eminli, S., Arnold, K., Stadtfeld, M., Yachechko, R., Tchieu, J., Jaenisch, R., et al. 2007. Directly reprogrammed fibroblasts show global epigenetic remodeling and widespread tissue contribution. Cell Stem Cell 1: 55-70.

Mandal, L., Banerjee, U., and Hartenstein, V. 2004. Evidence for a fruit fly hemangioblast and similarities between lymphgland hematopoiesis in fruit fly and mammal aorta-gonadalmesonephros mesoderm. Nat. Genet. 36: 1019-1023.

Mandal, L., Martinez-Agosto, J.A., Evans, C.J., Hartenstein, V., and Banerjee, U. 2007. A Hedgehog- and Antennapedia-dependent niche maintains Drosophila haematopoietic precur- 
sors. Nature 446: 320-324.

Margolis, J. and Spradling, A. 1995. Identification and behavior of epithelial stem cells in the Drosophila ovary. Development 121: 3797-3807.

Mikkola, H.K. and Orkin, S.H. 2006. The journey of developing hematopoietic stem cells. Development 133: 3733-3744.

Montgomery, J. and Coward, S. 1974. On the minimal size of a planarian capable of regeneration. Trans. Am. Microsc. Soc. 93: $386-391$.

Morrison, S.J. and Kimble, J. 2006. Asymmetric and symmetric stem-cell divisions in development and cancer. Nature 441: 1068-1074.

Morrison, S.J., Uchida, N., and Weissman, I.L. 1995. The biology of hematopoietic stem cells. Annu. Rev. Cell Dev. Biol. 11: 35-71.

Moser, M., Yu, Q., Bode, C., Xiong, J.-W., and Patterson, C. 2007. BMPER is a conserved regulator of hematopoietic and vascular development in zebrafish. J. Mol. Cell. Cardiol. 43: 243-253.

Murayama, E., Kissa, K., Zapata, A., Mordelet, E., Briolat, V., Lin, H.-F., Handin, R.I., and Herbomel, P. 2006. Tracing hematopoietic precursor migration to successive hematopoietic organs during zebrafish development. Immunity 25: 963-975.

Nagaraj, R. and Banerjee, U. 2003. Reiterative and concurrent use of EGFR and notch signaling during Drosophila eye development. In Handbook of cell signaling (eds. R. Bradshaw and E. Dennis), pp. 827-831. Elsevier Science, New York.

Nikolova, G., Strilic, B., and Lammert, E. 2007. The vascular niche and its basement membrane. Trends Cell Biol. 17: $19-25$.

Nishikawa, M., Tahara, T., Hinohara, A., Miyajima, A., Nakahata, T., and Shimosaka, A. 2001. Role of the microenvironment of the embryonic aorta-gonad-mesonephros region in hematopoiesis. Ann. N. Y. Acad. Sci. 938: 109-116.

North, T.E., de Bruijn, M.F.T.R., Stacy, T., Talebian, L., Lind, E., Robin, C., Binder, M., Dzierzak, E., and Speck, N.A. 2002. Runx1 expression marks long-term repopulating hematopoietic stem cells in the midgestation mouse embryo. Immunity 16: 661-672.

North, T.E., Stacy, T., Matheny, C.J., Speck, N.A., and de Bruijn, M.F.T.R. 2004. Runx1 is expressed in adult mouse hematopoietic stem cells and differentiating myeloid and lymphoid cells, but not in maturing erythroid cells. Stem Cells 22: 158-168.

Ohlstein, B. and Spradling, A. 2006. The adult Drosophila posterior midgut is maintained by pluripotent stem cells. $\mathrm{Na}$ ture 439: 470-474.

Okita, K., Ichisaka, T., and Yamanaka, S. 2007. Generation of germline-competent induced pluripotent stem cells. Nature 448: 313-317.

Osawa, M., Hanada, K.-i., Hamada, H., and Nakauchi, H. 1996. Long-term lymphohematopoietic reconstitution by a single CD34-low/negative hematopoietic stem cell. Science 273: 242-245.

Ottersbach, K. and Dzierzak, E. 2005. The murine placenta contains hematopoietic stem cells within the vascular labyrinth region. Dev. Cell 8: 377-387.

Palis, J., Robertson, S., Kennedy, M., Wall, C., and Keller, G. 1999. Development of erythroid and myeloid progenitors in the yolk sac and embryo proper of the mouse. Development 126: $5073-5084$

Park, I.K., Qian, D., Kiel, M., Becker, M.W., Pihalja, M., Weissman, I.L., Morrison, S.J., and Clarke, M.F. 2003. Bmi-1 is required for maintenance of adult self-renewing haematopoietic stem cells. Nature 423: 302-305.
Passegue, E., Jamieson, C.H., Ailles, L.E., and Weissman, I.L. 2003. Normal and leukemic hematopoiesis: Are leukemias a stem cell disorder or a reacquisition of stem cell characteristics? Proc. Natl. Acad. Sci. 100 (Suppl. 1): 11842-11849.

Qian, F., Zhen, F., Xu, J., Huang, M., Li, W., and Wen, Z. 2007. Distinct functions for different scl isoforms in zebrafish primitive and definitive hematopoiesis. PLOS Biol. 5: e132. doi: 10.1371/journal.pbio.0050132.

Qiao, D., Zeeman, A.-M., Deng, W., Looijenga, L.H.J., and Lin, H. 2002. Molecular characterization of hiwi, a human member of the piwi gene family whose overexpression is correlated to seminomas. Oncogene 21: 3988-3999.

Quesenberry, P.J., Colvin, G., and Abedi, M. 2005. Perspective: Fundamental and clinical concepts on stem cell homing and engraftment: A journey to niches and beyond. Exp. Hematol. 33: 9-19.

Rakic, P. 2006. A century of progress in corticoneurogenesis: From silver impregnation to genetic engineering. Cereb. Cortex 16: 3-17.

Ramalho-Santos, M., Melton, D.A., and McMahon, A.P. 2000. Hedgehog signals regulate multiple aspects of gastrointestinal development. Development 127: 2763-2772.

Reddien, P.W. and Alvarado, A.S. 2004. Fundamentals of planarian regeneration. Annu. Rev. Cell Dev. Biol. 20: 725-757.

Reddien, P.W., Oviedo, N.J., Jennings, J.R., Jenkin, J.C., and Alvarado, A.S. 2005. SMEDWI-2 is a PIWI-like protein that regulates planarian stem cells. Science 310: 1327-1330.

Reya, T. and Clevers, H. 2005. Wnt signalling in stem cells and cancer. Nature 434: 843-850.

Rossant, J. 2006. Stem cells and lineage development in the mammalian blastocyst. Reprod. Fertil. Dev. 19: 111-118.

Saló, E. 2006. The power of regeneration and the stem-cell kingdom: Freshwater planarians (Platyhelminthes). Bioessays 28: 546-559.

Salvetti, A., Rossi, L., Lena, A., Batistoni, R., Deri, P., Rainaldi, G., Locci, M.T., Evangelista, M., and Gremigni, V. 2005. DjPum, a homologue of Drosophila Pumilio, is essential to planarian stem cell maintenance. Development 132: 18631874.

Samokhvalov, I.M., Samokhvalova, N.I., and Nishikawa, S.-i. 2007. Cell tracing shows the contribution of the yolk sac to adult haematopoiesis. Nature 446: 1056-1061.

Scadden, D.T. 2006. The stem-cell niche as an entity of action. Nature 441: 1075-1079.

Schenke-Layland, K., Angelis, E., Rhodes, K.E., HeydarkhanHagvall, S., Mikkola, H.K., and MacLellan, W.R. 2007. Collagen IV induces trophoectoderm differentiation of mouse embryonic stem cells. Stem Cells 25: 1529-1538.

Schofield, R. 1978. The relationship between the spleen colonyforming cell and the haemopoietic stem cell. Blood Cells 4: $7-25$.

Seto, A.G., Kingston, R.E., and Lau, N.C. 2007. The coming of age for Piwi proteins. Mol. Cell 26: 603-609.

Soderhall, I., Bangyeekhun, E., Mayo, S., and Soderhall, K. 2003. Hemocyte production and maturation in an invertebrate animal; Proliferation and gene expression in hematopoietic stem cells of Pacifastacus leniusculus. Dev. Comp. Immunol. 27: 661-672.

Song, X., Zhu, C.-H., Doan, C., and Xie, T. 2002. Germline stem cells anchored by adherens junctions in the Drosophila ovary niches. Science 296: 1855-1857.

Songhet, P., Adzic, D., Reibe, S., and Rohr, K.B. 2007. fgf1 is required for normal differentiation of erythrocytes in zebrafish primitive hematopoiesis. Dev. Dyn. 236: 633-643.

Spangrude, G.J., Heimfeld, S., and Weissman, I.L. 1988. Purification and characterization of mouse hematopoietic stem 
cells. Science 241: 58-62.

Spassov, D.S. and Jurecic, R. 2003. Mouse Pum1 and Pum2 genes, members of the Pumilio family of RNA-binding proteins, show differential expression in fetal and adult hematopoietic stem cells and progenitors. Blood Cells Mol. Dis. 30: 55-69.

Szakmary, A., Cox, D.N., Wang, Z., and Lin, H. 2005. Regulatory relationship among piwi, pumilio, and bag-of-marbles in Drosophila germline stem cell self-renewal and differentiation. Curr. Biol. 15: 171-178.

Tepass, U., Fessler, L.I., Aziz, A., and Hartenstein, V. 1994. Embryonic origin of hemocytes and their relationship to cell death in Drosophila. Development 120: 1829-1837.

Terunuma, A., Shaya, M.B., Udey, M.C., and Vogel, J.C. 2004. An in vivo competitive repopulation assay system to evaluate human keratinocyte stem cells. J. Invest. Dermatol. 123: 993-995.

Thompson, M.A., Ransom, D.G., Pratt, S.J., MacLennan, H., Kieran, M.W., Detrich, H.W., Vail, B., Huber, T.L., Paw, B., Brownlie, A.J., et al. 1998. The cloche and spadetail genes differentially affect hematopoiesis and vasculogenesis. Dev. Biol. 197: 248-269.

Tiede, S., Kloepper, J.E., Bodo, E., Tiwari, S., Kruse, C., and Paus, R. 2007. Hair follicle stem cells: Walking the maze. Eur. J. Cell Biol. 86: 355-376.

Tober, J., Koniski, A., McGrath, K.E., Vemishetti, R., Emerson, R., de Mesy-Bentley, K.K., Waugh, R., and Palis, J. 2007. The megakaryocyte lineage originates from hemangioblast precursors and is an integral component both of primitive and of definitive hematopoiesis. Blood 109: 1433-1441.

Traver, D., Paw, B.H., Poss, K.D., Penberthy, W.T., Lin, S., and Zon, L.I. 2003. Transplantation and in vivo imaging of multilineage engraftment in zebrafish bloodless mutants. Nat. Immunol. 4: 1238-1246.

Traver, D., Winzeler, A., Stern, H.M., Mayhall, E.A., Langenau, D.M., Kutok, J.L., Look, A.T., and Zon, L.I. 2004. Effects of lethal irradiation in zebrafish and rescue by hematopoietic cell transplantation. Blood 104: 1298-1305.

Trowbridge, J.J., Scott, M.P., and Bhatia, M. 2006. Hedgehog modulates cell cycle regulators in stem cells to control hematopoietic regeneration. Proc. Natl. Acad. Sci. 103: 1413414139.

Tsinkalovsky, O., Vik-Mo, A.O., Ferreira, S., Laerum, O.D., and Fjose, A. 2007. Zebrafish kidney marrow contains ABCG2dependent side population cells exhibiting hematopoietic stem cell properties. Differentiation 75: 175-183.

Tulina, N. and Matunis, E. 2001. Control of stem cell self-renewal in Drosophila spermatogenesis by JAK-STAT signaling. Science 294: 2546-2549.

Tumbar, T., Guasch, G., Greco, V., Blanpain, C., Lowry, W.E., Rendl, M., and Fuchs, E. 2004. Defining the epithelial stem cell niche in skin. Science 303: 359-363.

Urbach, R. and Technau, G.M. 2004. Neuroblast formation and patterning during early brain development in Drosophila. Bioessays 26: 739-751.

Verdeil, J.-L., Alemanno, L., Niemenak, N., and Tranbarger, T.J. 2007. Pluripotent versus totipotent plant stem cells: Dependence versus autonomy? Trends Plant Sci. 12: 245-252.

Visnjic, D., Kalajzic, Z., Rowe, D.W., Katavic, V., Lorenzo, J., and Aguila, H.L. 2004. Hematopoiesis is severely altered in mice with an induced osteoblast deficiency. Blood 103: 3258-3264.

Voas, M.G. and Rebay, I. 2004. Signal integration during development: Insights from the Drosophila eye. Dev. Dyn. 229: 162-175.

Walkley, C.R., Olsen, G.H., Dworkin, S., Fabb, S.A., Swann, J.,
McArthur, G.A., Westmoreland, S.V., Chambon, P., Scadden, D.T., and Purton, L.E. 2007a. A microenvironment-induced myeloproliferative syndrome caused by retinoic acid receptor $\gamma$ deficiency. Cell 129: 1097-1110.

Walkley, C.R., Shea, J.M., Sims, N.A., Purton, L.E., and Orkin, S.H. 2007b. Rb regulates interactions between hematopoietic stem cells and their bone marrow microenvironment. Cell 129: 1081-1095.

Wang, J.C. and Dick, J.E. 2005. Cancer stem cells: Lessons from leukemia. Trends Cell Biol. 15: 494-501.

Wang, Z. and Lin, H. 2004. Nanos maintains germline stem cell self-renewal by preventing differentiation. Science 303: 2016-2019.

Wang, X.-P., Suomalainen, M., Felszeghy, S., Zelarayan, L.C., Alonso, M.T., Plikus, M.V., Maas, R.L., Chuong, C.-M., Schimmang, T., and Thesleff, I. 2007. An integrated gene regulatory network controls stem cell proliferation in teeth. PLOS Biol. 5: e159. doi: 10.1371/journal.pbio.0050159.

Wernet, M.F. and Desplan, C. 2004. Building a retinal mosaic: Cell-fate decision in the fly eye. Trends Cell Biol. 14: 576584.

Wernig, M., Meissner, A., Foreman, R., Brambrink, T., Ku, M., Hochedlinger, K., Bernstein, B.E., and Jaenisch, R. 2007. In vitro reprogramming of fibroblasts into a pluripotent ES-celllike state. Nature 448: 318-324.

Williams, M.J. 2007. Drosophila hemopoiesis and cellular immunity. J. Immunol. 178: 4711-4716.

Wilson, A. and Trumpp, A. 2006. Bone-marrow haematopoieticstem-cell niches. Nat. Rev. Immunol. 6: 93-106.

Wilson, A., Murphy, M.J., Oskarsson, T., Kaloulis, K., Bettess, M.D., Oser, G.M., Pasche, A.C., Knabenhans, C., Macdonald, H.R., and Trumpp, A. 2004. c-Myc controls the balance between hematopoietic stem cell self-renewal and differentiation. Genes \& Dev. 18: 2747-2763.

Wu, A.M., Till, J.E., Siminovitch, L., and McCulloch, E.A. 1967. A cytological study of the capacity for differentiation of normal hemopoietic colony-forming cells. J. Cell. Physiol. 69: 177-184.

Wu, A.M., Till, J.E., Siminovitch, L., and McCulloch, E.A. 1968. Cytological evidence for a relationship between normal hematopoietic colony-forming cells and cells of the lymphoid system. J. Exp. Med. 127: 455-464.

Xie, T. and Spradling, A.C. 1998. decapentaplegic is essential for the maintenance and division of germline stem cells in the Drosophila ovary. Cell 94: 251-260.

Xie, T. and Spradling, A.C. 2000. A niche maintaining germ line stem cells in the Drosophila ovary. Science 290: 328-330.

$\mathrm{Xu}$, E.Y., Chang, R., Salmon, N.A., and Pera, R.A.R. 2007. A gene trap mutation of a murine homolog of the Drosophila stem cell factor Pumilio results in smaller testes but does not affect litter size or fertility. Mol. Reprod. Dev. 74: 912 921.

Yamashita, Y.M., Fuller, M.T., and Jones, D.L. 2005. Signaling in stem cell niches: Lessons from the Drosophila germline. J. Cell Sci. 118: 665-672.

Yamashita, Y.M., Mahowald, A.P., Perlin, J.R., and Fuller, M.T. 2007. Asymmetric inheritance of mother versus daughter centrosome in stem cell division. Science 315: 518-521.

Ying, Q.-L., Nichols, J., Chambers, I., and Smith, A. 2003. BMP induction of Id proteins suppresses differentiation and sustains embryonic stem cell self-renewal in collaboration with STAT3. Cell 115: 281-292.

Yu, F., Kuo, C.T., and Jan, Y.N. 2006. Drosophila neuroblast asymmetric cell division: Recent advances and implications for stem cell biology. Neuron 51: 13-20.

Zhang, Y. and Kalderon, D. 2001. Hedgehog acts as a somatic 
Martinez-Agosto et al.

stem cell factor in the Drosophila ovary. Nature 410: 599604.

Zhang, C.C. and Lodish, H.F. 2004. Insulin-like growth factor 2 expressed in a novel fetal liver cell population is a growth factor for hematopoietic stem cells. Blood 103: 2513-2521.

Zhang, X.Y. and Rodaway, A.R.F. 2007. SCL-GFP transgenic zebrafish: In vivo imaging of blood and endothelial development and identification of the initial site of definitive hematopoiesis. Dev. Biol. 307: 179-194.

Zhang, J., Niu, C., Ye, L., Huang, H., He, X., Tong, W.-G., Ross, J., Haug, J., Johnson, T., Feng, J.Q., et al. 2003. Identification of the haematopoietic stem cell niche and control of the niche size. Nature 425: 836-841.

Zhang, C.C., Kaba, M., Ge, G., Xie, K., Tong, W., Hug, C., and Lodish, H.F. 2006. Angiopoietin-like proteins stimulate ex vivo expansion of hematopoietic stem cells. Nat. Med. 12: 240-245.

Zhou, M., Li, X.-m., and Lavker, R.M. 2006. Transcriptional profiling of enriched populations of stem cells versus transient amplifying cells: A comparison of limbal and corneal epithelial basal cells. J. Biol. Chem. 281: 19600-19609. 


\section{The hematopoietic stem cell and its niche: a comparative view}

Julian A. Martinez-Agosto, Hanna K.A. Mikkola, Volker Hartenstein, et al.

Genes Dev. 2007, 21:

Access the most recent version at doi:10.1101/gad.1602607

References

This article cites 162 articles, 58 of which can be accessed free at: http://genesdev.cshlp.org/content/21/23/3044.full.html\#ref-list-1

License

Email Alerting

Service

Receive free email alerts when new articles cite this article - sign up in the box at the top right corner of the article or click here.

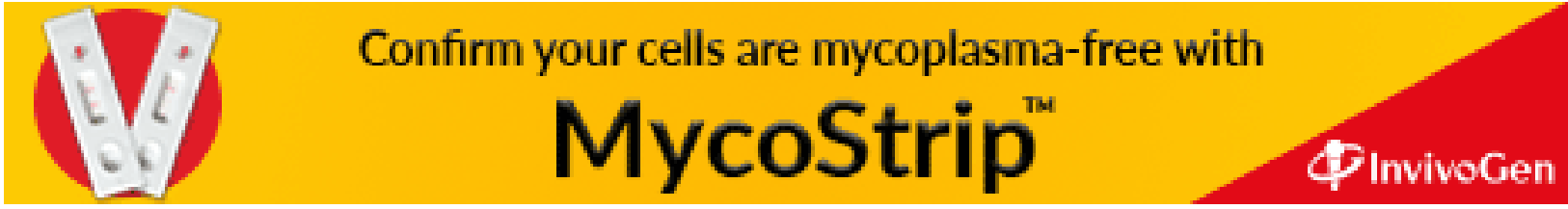

Copyright @ 2007, Cold Spring Harbor Laboratory Press 